\title{
Maximal Sprint Speeds and Muscle Fiber Composition of Wild and Laboratory House Mice
}

\author{
THECDORE GARLAND, JR., ${ }^{* 1}$ TODD T. GLEESON, $†$ BENJAMIN A. ARONOVITZ, $\dagger$ \\ CHRISTOPHER S. RICHARDSON, ${ }^{*} \ddagger$ AND MICHAEL R. DOHM* $§$
}

\author{
*Department of Zoology, 430 Lincoln Drive, University of Wisconsin, Madison, WI 53706-1381 Email: \\ tgarland@macc.wisc.edu, and †Department of Environmental, Population, and Organismic Biology, University of \\ Colorado, Boulder, CO 80309-0334
}

Received 13 October 1994

\begin{abstract}
GARLAND, T., JR., T. T. GLEESON, B. A. ARONOVITZ, C. S. RICHARDSON AND M. R. DOHM. Maximal sprint speeds and muscle fiber composition of wild and laboratory house mice. PHYSIOL BEHAV 58(5) 869-876, 1995.-We compared males from four groups of house mice (Mus domesticus), all bred and raised under common conditions in the laboratory: randombred Hsd:ICR; a wild population from Wisconsin; hybrids from lab dams; hybrids from wild dams. Wild mice were much faster sprinters (maximal forced sprint speeds over $1.0 \mathrm{~m}$ ranged from 2.38 to $3.34 \mathrm{~m} / \mathrm{s}$ ) than were lab mice (range $=0.89-1.68 \mathrm{~m} / \mathrm{s}$ ). Hybrids exhibited intermediate speeds (range $=1.54-2.70$ $\mathrm{m} / \mathrm{s}$ ) and body masses, indicating largely additive inheritance. Type-specific mean muscle fiber cross-sectional areas of the gastrocnemius muscle did not differ significantly among groups. Percentage cross-sectional areas occupied by each of the three identified fiber types also did not differ significantly among groups, nor did they covary with body mass. For their body mass, however, lab mice had smaller gastrocnemius muscles than did wild and hybrid mice, which had muscles of similar size. Although we cannot rule out the possibility that smaller gastrocnemius muscles or slight differences in fiber composition account for the lower sprint speeds of the lab mice, we suggest that differences in unmeasured physiological, behavioral or motivational factors are probably the primary cause. This interpretation is supported by a lack of correlation between individual differences in sprint speed and either relative gastrocnemius muscle mass or muscle fiber type composition.
\end{abstract}

$\begin{array}{llrlcc}\text { Body mass } & \text { Domestication } & \text { Exercise } & \text { Fiber types } & \text { Genetics } & \text { House mouse } \\ \text { Inheritance } & \text { Locomotion } & \text { Motivation } & \text { Performance } & \text { Speed } & \text { Mus }\end{array}$

DOMESTICATION of animals results in many behavioral and physiological changes (e.g., 6,26,27,34,38). An understanding of these changes has obvious implications with respect to many economically important organisms, but it is also of interest to evolutionary biologists. Domestication is best thought of as a process of adaptation to altered environmental conditions or, more specifically, "domestication is the adaptation of animals to environmental circumstances defined by humans ..." $(24$, p. 31$)$.

One way to study changes that have occurred during domestication is to compare wild and domesticated forms of the same species. If both forms are bred and raised under common environmental conditions (a "common garden" experiment), then any phenotypic differences between the forms can generally be ascribed to genetic causes, although maternal influences often cannot be entirely ruled out (e.g., review in 14).

House mice (Mus domesticus) have been proposed as appropriate models for the study of domestication as an evolutionary process $(8,39)$, and many "common garden" comparisons of wild and lab house mice have been performed. As compared with house mice captured in the wild (usually living commensally), lab strains typically exhibit many differences, including less responsiveness to environmental cues affecting reproduction, higher growth rates, and much more docile temperaments $(6,34,38)$. As part of a larger research program using house mice as a model system for quantitative genetic analyses (10) of questions derived from evolutionary physiology $(13,15,21)$, we

\footnotetext{
${ }^{1}$ To whom requests for reprints should be addressed.

$\ddagger$ Present address: Department of Biology, Boston University, Boston, MA 02215.

$\S$ Present address: Department of Biological Sciences, Stanford University, Stanford, CA 94305.
} 
have compared a randombred strain of laboratory house mice (Hsd:ICR) with wild mice captured from a commensal Wisconsin population. In this comparison, we also found many differences, such as the lab mice being larger at all ages postweaning and displaying less voluntary activity on running wheels $(11,35)$.

Of the traits studied in these previous comparisons, forced maximal sprint running speed (measured on a photocell-lined racetrack) showed the largest difference, with wild mice averaging over twice as fast as the lab mice and the distributions of speeds showing no overlap (11). The purpose of the present study was to determine whether this difference was reflected at the level of muscle fiber composition. Fiber type proportions correlate with differences in athletic performance among groups of human athletes, lower primates, rodents, ungulates, and among breeds of horses and dogs (e.g., 1,9,20,22,36,40). Fiber type proportions have also been shown to correlate with individual differences in locomotor abilities in lizards and in humans (e.g., $12,18,25)$. Our second goal, therefore, was to determine whether individual differences in sprint speed of mice were correlated with the mass of the gastrocnemius muscle (an important ankle flexor) or the percentage cross-sectional area occupied by each of three major skeletal muscle fiber types (cf. 3,13).

\section{METHOD}

We studied house mice (Mus domesticus) of four types, as described in detail in the companion papers $(11,35)$. Laboratory mice were of the randombred, genetically variable Hsd:ICR strain, purchased from Harlan Sprague-Dawley, Indianapolis, IN (Bldg. 202, Barrier A) [see (10) for further details]. Wild mice were captured from a barn in Dane Co., Wisconsin (35). Hybrid individuals (wild dam $\times$ lab sire, lab dam $\times$ wild sire) were also studied. All breeder mice were housed under standardized conditions in our laboratory and mated to produce the "lab," "wild," and "hybrid" offspring used for the present experiments. This "common garden" experimental design was used because we wished to know whether any differences between lab and wild mice were of genetic as opposed to environmental origin (see 14). We tested only males because the female siblings were used in the companion studies. To ensure independence of data points, we generally used only a single (randomly chosen) individual from each family (separate parental pair); however, to increase sample size for sprint speed measurements, we also used a second individual from each of four wild $\times$ wild families and from each of four lab $\times$ lab families. Thus, the 35 mice measured for speed derived from 27 separate parental pairs.

Forced maximal sprint running speeds were measured on an 7 -m long by $7.5 \mathrm{~cm}$ wide photocell-lined racetrack, with short-pile plastic artificial grass substrate $(11$, see also 10,13$)$. The racetrack had sheet metal walls which extended above the substrate $27 \mathrm{~cm}$ on one side and $50 \mathrm{~cm}$ on the other. Twelve sets of photocells spaced at $0.5 \mathrm{~m}$ intervals (first set at $1.0 \mathrm{~m}$ from start) were interfaced to a computer. Each individual was tested five times in quick succession on each of two consecutive days. Mice were chased along the racetrack with a meter stick covered with cardboard $(6.5 \times 30 \mathrm{~cm})$ as fast as they would run; they were then gently encouraged to walk back to the start of the track. The fastest $1.0 \mathrm{~m}$ intervals (three consecutive photocell stations) from each trial day were compared to assess repeatability; the single fastest $1.0 \mathrm{~m}$ ever recorded was analyzed as "maximal" sprint running speed.

Mice were sacrificed by cervical dislocation and their left and right gastrocnemius muscles were dissected free, blotted, and weighed to the nearest $1.0 \mathrm{mg}$ Muscles were suspended at slack length and frozen in an isopentane bath cooled with liquid nitrogen and stored at $-74^{\circ} \mathrm{C}$ until histochemical analysis.
Frozen muscles were mounted to chucks with Tissuetek ${ }^{\mathrm{TM}}$ and serial transverse sections $(10 \mu \mathrm{m}$ thick) were cut from the mid-belly region of the muscle in an AO cryostat. Serial sections of each muscle were incubated at $37^{\circ} \mathrm{C}$ with appropriate reactants to demonstrate alkaline-stable myosin ATPase (mATPase; 10 min, $\mathrm{pH}$ 9.4) and succinic dehydrogenase/NADH diaphorase $(\mathrm{SDH} ; 30 \mathrm{~min}, \mathrm{pH} 7.4)$ as described in (19). Histochemical activities of the two enzymes were used to identify slow twitchoxidative fibers (SO; light mATPase, dark SDH), fast twitchoxidative glycolytic (FOG; dark mATPase, dark SDH) fibers, and fast twitch-glycolytic fibers (FG; dark mATPase, light SDH) as first defined by Peter et al. (30). This classification scheme is roughly equivalent to the Type I, IIa, and IIb nomenclature, respectively, described by Brooke and Kaiser (7). Preliminary incubations to demonstrate $\alpha$-glycerophosphate dehydrogenase activity were used to confirm the glycolytic nature of the above fiber classification. Color video images of the mounted sections were captured under $40 \mathrm{X}$ magnification using a $\mathrm{CCD}$ video camera and Cue II imaging software (Olympus, Inc.) run on a Zenith 286 computer. Area determinations of fibers and muscle areas were made using digitizing Cue II subroutines calibrated by projecting a stage micrometer at the same magnification. Digitizing errors were inversely proportional to object size. Repeated measurement $(n=10)$ of large $\left(9,825 \mu \mathrm{m}^{2}\right)$ and small $(2,150$ $\mu \mathrm{m}^{2}$ ) fibers yielded standard errors of estimates of the mean of $0.69 \%-1.05 \%$, respectively. Total cross-sectional area occupied by each fiber type was determined by dividing the muscle cross-section into 3-7 regions (mean $=5.5 \pm 0.82 \mathrm{SD}, n=30$ ) of uniform fiber type composition and measuring the cross-sectional area represented by each region. Regionalization of muscle cross-sections did not differ among groups $[F(3,26)=1.711$, $p=0.189$ ]. Fiber size was determined by measuring the crosssectional area of five fibers of each type within each region. Fibers were selected for digitizing based upon their coincidence with intersections of a $229 \mu \mathrm{m} 10 \times 7$ grid overlain on the video image. Fiber type composition of each region was determined by simultaneously displaying video images of mATPase and SDH incubated serial sections using Photoshop version 2.0.1 software on a Macintosh IIci computer. Fiber composition within each area was determined by counting the number of each fiber type falling along each of four linear transects projected across each region. Total number of fibers counted in each area of each muscle averaged $41 \pm 16.5 \mathrm{SD}(n=164$, range 16-98) and did not differ significantly among groups $[F(3,160)=2.472, p=$ 0.0637]. An Excel spreadsheet was used to calculate mean muscle fiber type composition and mean fiber areas based upon weighted averages for each analyzed region of the muscle.

Statistical analyses were performed using SPSS $/ \mathrm{PC}+$ version 5.0, with the a priori significance level set at $p=0.05$. Possible differences in sprint speed between trial days were tested using paired $t$-tests. Repeatability of sprint speeds was indexed with an ordinary Pearson product-moment correlation coefficient, which is insensitive to differences in mean values between trial days. Analysis of variance (ANOVA) and analysis of covariance (ANCOVA) were used to compare mean values of the four groups; these analyses were implemented both in the ONEWAY and ANOVA (which allows covariates) procedures of SPSS, and with dummy variables in a multiple regression using the REGRESSION procedure. The two hybrid groups were compared to check for possible maternal effects (see 11,35).

We also tested whether individual differences in sprint speed were correlated with muscle mass or fiber type composition. We first corrected all groups to the same mean value by computing residuals from multiple regression equations with three dummy variables coding for group membership (as compared with lab 
mice). We then correlated these adjusted values. Gastrocnemius muscle mass and fiber sizes were correlated with body mass, so mass was included as an independent variable when computing residuals. Neither body mass nor age was ever a significant covariate of any of the other characters measured, so these were not included in the regression equations used to compute residuals.

\section{RESULTS}

\section{Speed}

Forced sprint running speeds were generally consistent between trial days, both among groups and among individuals within the four groups (Fig. 1). This reproducibility demonstrates that our measures are good enough to serve as indicators of individual differences in sprint speed (see below), as well as to test for group differences. Pearson product-moment correlations $(r)$ between highest speeds recorded on trial days one and two were 0.899 for all 35 mice (2-tailed $p<0.0001$ ), 0.646 for the nine wild mice $(p=0.060), 0.290$ for the seven wild dam hybrids $(p=0.528), 0.778$ for the 7 lab dam hybrids $(p=0.039)$, and 0.787 for the 12 lab mice $(p=0.002)$.

Figure 1 also shows that wild individuals tended to run more slowly on the second trial day (paired $t=-2.62,2$-tailed $p=$ 0.031 ), whereas lab mice showed the opposite trend (paired $t=3.49, p=0.005$ ). Previous studies in our lab have also found Hsd:ICR mice to run faster on the second trial day $(10,13)$. The behavior of the hybrid mice was intermediate to that of the wild and lab mice, as they exhibited no significant tendency to be faster on either trial day.

Considering the single highest ("maximal") sprint speed ever recorded (Fig. 2), analysis of variance indicated highly significant differences among the four groups $[F(3,31)=36.47, p<$ $0.0001]$. Wild individuals (mean $\pm \mathrm{SD}=2.83 \pm 0.388 \mathrm{~m} / \mathrm{s}, n=$ 9) were much faster on average than were lab mice (1.29 \pm 0.226 , $n=12$ ), and the ranges of sprint speeds did not overlap [wild range $=2.38-3.34 ;$ lab range $=0.89-1.68 \mathrm{~m} / \mathrm{s}$ : see also $(11)$ on

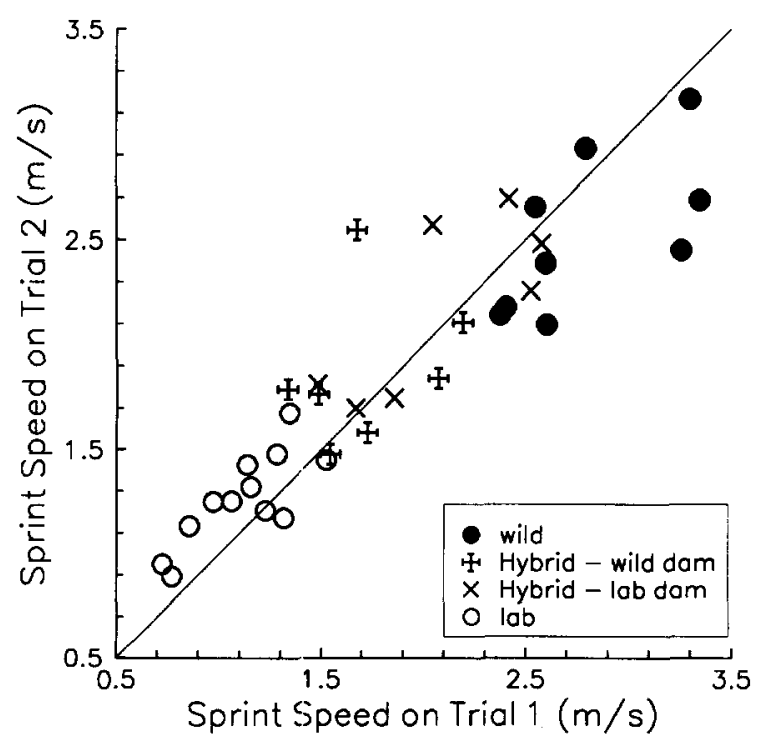

FIG. 1. Repeatability of highest forced sprint speeds (over $1.0 \mathrm{~m}$ ) recorded during five trials on each of two consecutive days. Solid line indicates perfect repeatability. Lab house mice tended to be faster on the second trial day, but wild mice showed the opposite trend (see text).

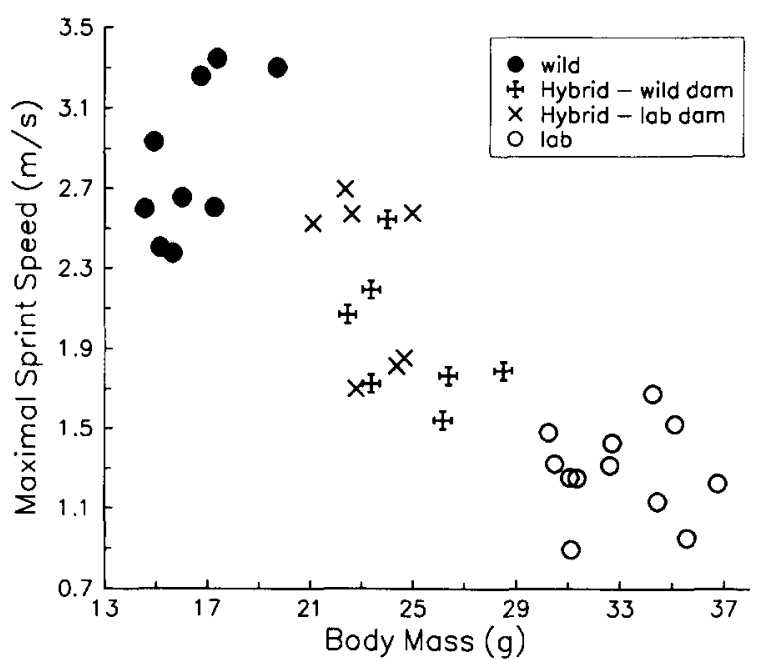

FIG. 2. Maximal recorded sprint speeds (highest on any trial) in relation to body mass for four groups of house mice, all of which were bred and raised in the laboratory under standardized conditions. Note that hybrid mice display body masses and sprint speeds that are intermediate between those of wild and lab mice. This intermediacy indicates that the genes causing differences between these wild and lab mice are largely additive in their effects.

females]. Both hybrid groups (both $n=7$ ) exhibited intermediate maximal sprint speeds (wild dam $1.95 \pm 0.343$, range $=1.54-$ $2.55 \mathrm{~m} / \mathrm{s}$; lab dam $2.25 \pm 0.436$, range $=1.70-2.70$ ). Although Levene's test indicated significant heterogeneity of variances among the four groups $[F(3,31)=4.42, p=0.011]$, which suggests caution in interpreting results of the ANOVA, the group differences were confirmed by a nonparametric Kruskal-Wallis 1 -way ANOVA (Chi-square $=27.82, p<0.0001$ ). Posthoc multiple range comparisons (based on the parametric ANOVA) indicated that both wild and lab mice differed significantly from all three other groups, but that the two hybrid groups did not differ significantly from each other (this last comparison was confirmed by a Mann-Whitney $U$-test: $U=13$, 2-tailed $p=$ 0.165 ).

Analysis of covariance indicated that neither body mass [ $F(1$, 29) $=0.000, p=0.993$, pooled within-groups (partial) $r=$ $-0.028]$ nor age $[F(1,29)=0.439, p=0.513]$ was a significant predictor of maximal sprint speed. In this analysis, the group effect was reduced to marginal significance $[F(3,29)=2.61$, $p=0.071$, in part because of the high correlation between body mass and group membership (see Fig. 2). Ignoring genetic background, the overall correlation between maximal sprint speed and body mass is $-0.851(p<0.0001)$. However, maximal sprint speed was neither consistently nor significantly correlated with body mass within any of the four groups (wild $r=0.646$, wild dam hybrid $r=-0.498$, lab dam hybrid $r=-0.381$, lab $r=$ -0.021 ; all 2-tailed $p>0.05$ : see Fig. 2). This lack of correlation is consistent both with theoretical expectations [Ch. 9 of (2), references in (16)] and with most empirical comparisons within and across species of mammals (16 and references therein), including our previous studies of Hsd:ICR house mice $(10,11,13)$. For example, in a quantitative genetic study of 347 Hsd:ICR mice (10), log maximal sprint speed was not significantly correlated with $\log$ body mass $(r=0.050 ; 2$-tailed $p=0.357)$. Thus, we conclude that the best statistical model of group differences in sprint speed is the simple ANOVA, without body mass (or age) as a covariate. 


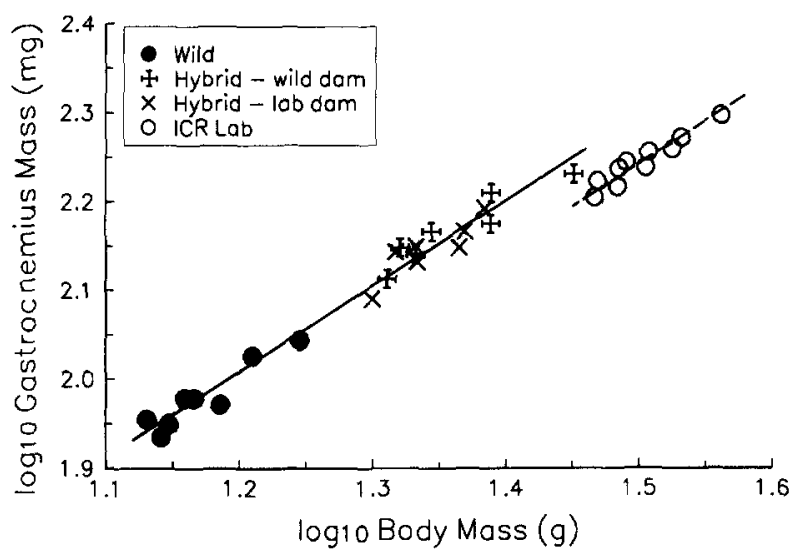

FIG. 3. Log-log plot of gastrocnemius muscle mass in relation to body mass. Analysis of covariance indicates that lab mice have significantly smaller relative gastrocnemius muscles than do pooled wild plus hybrid mice (see text). The pooled within-groups slope for this comparison ( $0.964=$ both solid and dashed lines) did not differ significantly from unity (95\% confidence interval $=0.90-1.02)$.

\section{Body Mass}

As shown in Fig. 2, body mass varied among groups in a fashion similar to the variation in maximal sprint speeds, and these differences were highly significant by ANOVA $[F(3,34)$ $=131.97, p<0.0001$ ]. Body mass of hybrid mice (wild dam mean $\pm \mathrm{SD}=24.91 \pm 2.166$, range $=22.5-28.5 \mathrm{~g}$; lab dam $23.27 \pm 1.433$, range $=21.1-25.0)$ was intermediate between, and did not overlap with, that of wild $(16.37 \pm 1.599$, range $=$ 14.6-19.7) and lab mice $(32.99 \pm 2.198$, range $=30.3-36.8)$.

The four groups of mice differed significantly in age at measurement of maximal sprint speed (overall range $=53-68$ days, $F(3,31)=4.46, p=0.0103)$, but the differences were not great (wild mean $\pm \mathrm{SD}=60.9 \pm 2.09$ days, wild dam hybrid $59.6 \pm 4.79$, lab dam hybrid $63.0 \pm 3.51$, lab $64.8 \pm 2.86$ ). These small differences in age did not account for the differences in body mass [ANCOVA: $F(1,30)$ for age effect $=1.71, p=0.201$; $F(3,30)$ for group effect $=107.38, p<0.001]$, and body mass was not significantly correlated with age within any of the four groups. Mice were four days older, on average, when sacrificed for muscle analyses, but the pattern of among-group differences in body mass was similar (see Figs. 3,4 ).

\section{Gastrocnemius Muscle Mass}

The correlation between left and right gastrocnemius muscle masses was very high $(n=32 ; r=0.988, r=0.982$ on the $\log$

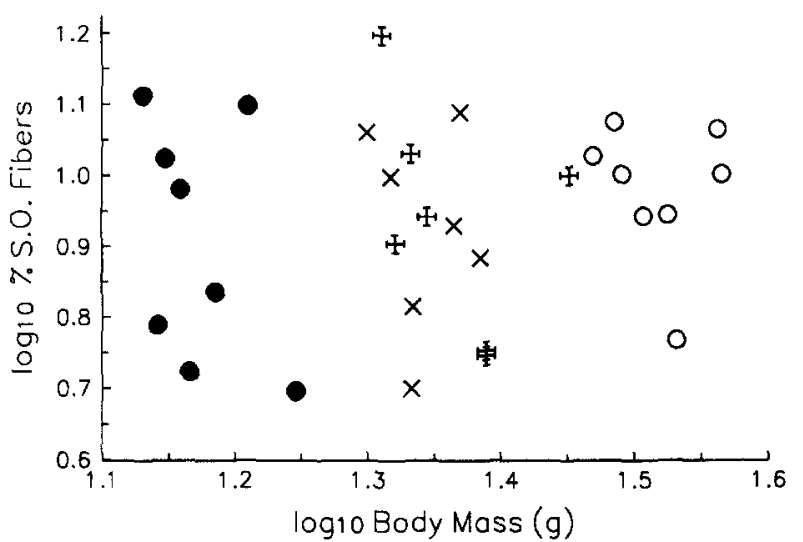

FIG. 4. Log-log plot of percent of the gastrocnemius muscle cross-sectional area occupied by slow twitch oxidative fibers in relation to body mass. As a percentage of total muscle fibers scored, none of the three fiber types distinguished in the present study showed significant differences among groups (see Table 1 and text) nor any significant tendency to covary with either body mass (see also Table 3 ) or age (which ranged from 56 to 77 days). Symbols as in Figs. 1-3.

scale). Thus, individual differences were apparent. Mean values were used for all analyses.

Lab mice had smaller gastrocnemius muscles for their body mass than did either wild or hybrid mice (Fig. 3). Analysis of covariance comparing lab with pooled wild plus hybrid mice indicated a highly significant effect of both group $[F(1,29)=$ $45.9, p<0.0001]$ and body mass $[F(1,29)=1,061.2, p<$ $0.0001]$. Pooling the wild and hybrid mice for comparison with the lab mice, as shown in Fig. 3, was justified because ANCOVA comparing the two hybrid groups indicated no significant difference $(p=0.4125)$ as did ANCOVA comparing the pooled hybrid mice with the wild mice $(p=0.1366)$. [See $(11,35)$ for further discussion on these statistical points with respect to other measured characters.] We also tried the ANCOVAs with age as a covariate, but age was never significant.

\section{Gastrocnemius Muscle Fiber Types}

Table 1 reports fiber type composition of gastrocnemius muscles for all four groups. Figure 4 shows that \% slow oxidative fibers in the gastrocnemius muscle did not vary among groups or in relation to body mass; this depiction is also representative for $\%$ FOG fibers and for \% FG fibers. None of the three fiber type populations showed any significant correlation with body mass or with age either within groups or for all mice combined (see also Table 3 and next section). Group differences in \% fiber type

TABLE 1

PERCENTAGE FIBER TYPES IN GASTROCNEMIUS MUSCLES OF FOUR GROUPS OF HOUSE MICE

\begin{tabular}{lcccc} 
& & & \multicolumn{2}{c}{ Hybrid } \\
\cline { 5 - 6 } Fiber Type & Wild (8) & Lab (8) & Wild dam (7) & Lab dam (7) \\
\hline Fast oxidative glycolytic & & & & \\
$\quad$ Mean \pm SD & $26.4 \pm 5.56$ & $22.7 \pm 5.63$ & $23.2 \pm 4.32$ & $24.5 \pm 3.98$ \\
$\quad$ Range & $18.6-36.5$ & $15.0-34.3$ & $17.6-28.1$ & $17.8-29.2$ \\
$\begin{array}{l}\text { Slow oxidative } \\
\quad \text { Mean } \pm \text { SD }\end{array}$ & $8.6 \pm 3.22$ & $9.7 \pm 1.93$ & $9.2 \pm 3.49$ & $8.8 \pm 2.63$ \\
$\quad$ Range & $5.0-12.9$ & $5.9-11.9$ & $5.6-15.7$ & $5.0-12.3$ \\
Fast glycolytic & & & & \\
$\quad$ Mean \pm SD & $65.0 \pm 5.16$ & $67.5 \pm 6.75$ & $67.6 \pm 6.80$ & $66.7 \pm 5.34$ \\
$\quad$ Range & $56.6-73.6$ & $54.1-75.3$ & $56.1-76.2$ & $59.2-73.7$ \\
\hline
\end{tabular}

Sample sizes are in parentheses. 
TABLE 2

FIBER TYPE AREAS IN GASTROCNEMIUS MUSCLES OF FOUR GROUPS OF HOUSE MICE

\begin{tabular}{|c|c|c|c|c|}
\hline \multirow[b]{2}{*}{ Fiber Type } & \multirow[b]{2}{*}{ Wild (8) } & \multirow[b]{2}{*}{ Lab (8) } & \multicolumn{2}{|c|}{ Hybrid } \\
\hline & & & Wild dam (7) & Lab dam ( 7$)$ \\
\hline $\begin{array}{c}\log _{10} \text { Body mass }(\mathrm{g}) \\
\text { Mean } \pm \text { SD }\end{array}$ & $1.17 \pm 0.039$ & $1.52 \pm 0.035$ & $1.36 \pm 0.050$ & $1.34 \pm 0.031$ \\
\hline $\begin{array}{l}\log _{10} \text { Fast oxidative } \\
\text { Mean } \pm \text { SD } \\
\text { Adjusted Mean }\end{array}$ & $\begin{array}{l}\text { Colytic }\left(\mathrm{mm}^{2}\right) \\
-2.97 \pm 0.051 \\
-2.95\end{array}$ & $\begin{array}{l}-2.89 \pm 0.042 \\
-2.88\end{array}$ & $\begin{array}{l}-2.91 \pm 0.038 \\
-2.91\end{array}$ & $\begin{array}{l}-2.89 \pm 0.069 \\
-2.92\end{array}$ \\
\hline $\log _{10}$ Slow oxidativ & $\left.\mathrm{nm}^{2}\right)$ & & & \\
\hline $\begin{array}{l}\text { Mean } \pm \text { SD } \\
\text { Adjusted Mean } \\
\text { log Fast glycolyti }\end{array}$ & $\begin{array}{l}-2.93 \pm 0.048 \\
-2.93 \\
\left.\mathrm{~nm}^{2}\right)\end{array}$ & $\begin{array}{l}-2.82 \pm 0.065 \\
-2.83\end{array}$ & $\begin{array}{l}-2.91 \pm 0.050 \\
-2.87\end{array}$ & $\begin{array}{l}-2.85 \pm 0.073 \\
-2.88\end{array}$ \\
\hline $\begin{array}{l}\text { Mean } \pm \text { SD } \\
\text { Adjusted Mean }\end{array}$ & $\begin{array}{l}-2.74 \pm 0.038 \\
-2.73\end{array}$ & $\begin{array}{l}-2.67 \pm 0.067 \\
-2.67\end{array}$ & $\begin{array}{l}-2.72 \pm 0.020 \\
-2.70\end{array}$ & $\begin{array}{l}-2.68 \pm 0.056 \\
-2.70\end{array}$ \\
\hline
\end{tabular}

Sample sizes are in parentheses. Four-group ANCOVAs with $\log _{10}$ body mass as the covariate indicated nonsignificant group differences (all $p>0.22$ ). Adjusted means are adjusted for log body mass, which was positively related to all three log fiber type areas.

composition were nonsignificant by ANOVA (all $\mathrm{df}=3,29$ : $\log$ $\%$ SO fibers $F=0.36, p=0.785$; \% FG fibers $F=0.31, p=$ $0.820 ; \log \%$ FOG fibers $F=0.85, p=0.479$ ), and post hoc multiple range comparisons indicated that no two groups differed significantly. Finally, comparing only wild and lab groups by ANOVA indicated no significant differences. Moreover, percentage fiber type composition data are not independent because they must sum to $100 \%$, so only two fiber types should be compared statistically; otherwise, Type I error rates will be inflated. Hence, we have been excessively liberal by statistically comparing (at $p=0.05$ ) groups for all three fiber types, and even so group differences never appear significant.

Fiber size (Table 2) also was not s:gnificantly different among groups. Although mean fiber cross-sectional areas for each fiber type were largest in lab mice and smallest in wild mice, with hybrids being intermediate, once body mass was included as a covariate, ANCOVA revealed no significant differences among groups ( $p>0.22$ for all three fiber types).

\section{Correlates of Individual Differences in Sprint Speed}

After removing group differences in mean values by computing residuals from multiple regression equations, maximal sprint

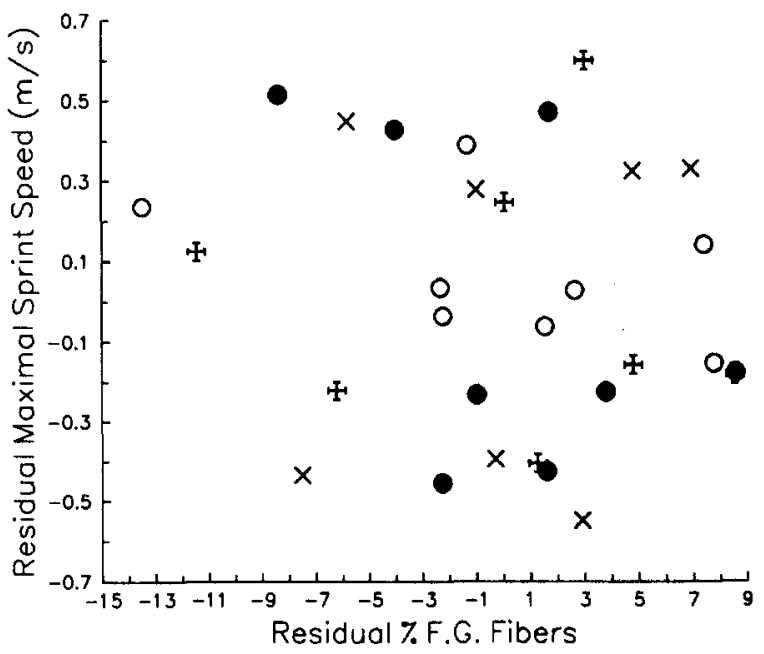

FIG. 5. Lack of relationship between residual (adjusted for differences in group means) maximal sprint speed and residual \% total cross-sectional area occupied by fast glycolytic fibers in the gastrocnemius muscle (see Table 3 for correlation coefficients). Symbols as in Figs. 1-3.

TABLE 3

CORRELATIONS OF INDIVIDUAL VARIATION IN SPRINT SPEED WITH MUSCLE CHARACTERS

\begin{tabular}{|c|c|c|c|c|c|}
\hline & $\begin{array}{l}\text { Body } \\
\text { Mass }\end{array}$ & $\begin{array}{l}\text { Gastroc. } \\
\text { Mass }\end{array}$ & $\begin{array}{l}\% \text { FOG } \\
\text { Fibers }\end{array}$ & $\begin{array}{l}\% \text { SO } \\
\text { Fibers }\end{array}$ & $\begin{array}{l}\% \text { FG } \\
\text { Fibers }\end{array}$ \\
\hline$\overline{\text { Maximal Sprint Speed }}$ & -0.028 & -0.016 & 0.154 & 0.055 & -0.164 \\
\hline & $\begin{array}{l}35 \\
0.875\end{array}$ & $\begin{array}{l}32 \\
0.931\end{array}$ & $\begin{array}{l}30 \\
0.415\end{array}$ & $\begin{array}{l}30 \\
0.773\end{array}$ & $\begin{array}{l}30 \\
0.388\end{array}$ \\
\hline Body Mass & & $\begin{array}{c}0.000 \$ \\
32 \\
1.00\end{array}$ & $\begin{array}{c}-0.096 \\
30 \\
0.613\end{array}$ & $\begin{array}{c}-0.288 \\
30 \\
0.123\end{array}$ & $\begin{array}{c}0.185 \\
30 \\
0.328\end{array}$ \\
\hline Gastrocnemius Mass & & & $\begin{array}{c}0.001 \\
29 \\
0.997\end{array}$ & $\begin{array}{c}-0.041 \\
29 \\
0.835\end{array}$ & $\begin{array}{c}0.050 \\
29 \\
0.795\end{array}$ \\
\hline $\log \%$ FOG Muscle Fibers & & & & $\begin{array}{c}0.115 \\
30 \\
0.544\end{array}$ & $\begin{array}{c}-0.877 \\
30 \\
<0.001\end{array}$ \\
\hline $\log \%$ SO Muscle Fibers & & & & & $\begin{array}{c}-0.563 \\
30 \\
0.001\end{array}$ \\
\hline
\end{tabular}

Differences among group means were removed statistically prior to computing correlations (see text). Values are Pearson product-moment correlations, sample size, and pairwise 2-tailed $p$ (unadjusted for multiple tests).

$\$$ This correlation is necessarily zero because log body mass was included as an independent variable when computing residual log gastrocnemius muscle mass. 
running speed was uncorrelated with body mass, relative gastrocnemius muscle mass, or percentage muscle fiber type composition (Table 3). Figure 5 shows the lack of relationship between sprint speed and \% fast glycolytic fibers. These correlations were also nonsignificant within each of the four groups (results not shown). Analyses using absolute fiber sizes instead of percentages also revealed no significant correlations with sprint speed (results not shown).

As noted in the previous section, the measures of percentage fiber types are not independent. This nonindependence is shown in Table 3 as correlations between the three different \% fiber type variables.

\section{DISCUSSION}

Wild and randombred male house mice, bred and raised under standardized conditions in the laboratory, showed very different forced maximal sprint running speeds, with hybrids between these two populations showing intermediate phenotypes (Figs. 1, 2). Fiber type composition of the gastrocnemius muscle, an important ankle flexor, showed a similar pattern (Fig. 4, Tables 1, 2), but group differences were not statistically significant. Post hoc power analyses indicated relatively low power to detect significant $(p=0.05)$ differences with the sample sizes employed. For example, in a multiple regression using three dummy variables to compare wild and hybrid groups with the lab mice, statistical power of the comparison of wild vs. lab mice (these being the two groups showing the largest difference-see Table 1) was computed to be approximately $50 \%$ for $\log \%$ FOG, $26 \%$ for $\log \% \mathrm{SO}$, and only $20 \%$ for $\% \mathrm{FG}$. Thus, we cannot rule out the possibility that group differences in sprint speed are at least partly attributable to differences in fiber composition of the gastrocnemius muscle. Nevertheless, the magnitude of group differences in fiber composition (Fig. 4, Tables 1, 2) is clearly nowhere near as great as for sprint speed, which did not even overlap between wild and lab mice (Fig. 2 and RESULTS).

Smaller gastrocnemius muscles (Fig. 3) might also account in part for the lower sprint speeds of the lab mice. Several lines of evidence, however, indicate that relatively small gastrocnemius muscles cannot be the entire cause of the low sprint speeds of lab Iiilce. First, although speeds of the hybrid mice were intermediate between those of wild and lab mice (Figs. 1, 2) their gastrocnemius muscles were not of intermediate size for their body mass (Fig. 3). Second, in the present study, individual differences in speed did not correlate with residual gastrocnemius mass (Table 3). Third, in another study of $305 \mathrm{Hsd}$ :ICR mice of both sexes we also found no significant correlation between residual maximal sprint speed and residual gastrocnemius mass $[r=0.079,2$-tailed $p=0.168 ;(10)]$. Finally, as noted in the companion papers $(11,35)$, differences in lean body mass (not measured) could also account for some of the difference in gastrocnemius mass relative to body mass (Fig. 3).

Dohm et al. (11) reported no significant group differences in gastrocnemius muscle mass for the female siblings of the male mice studied herein, although the trend was similar to what we observed (Fig. 3). Only the right gastrocnemius was weighed in the previous study, however, which should increase measurement error and hence decrease statistical power. On the other hand, some other differences between our results and those reported in the companion papers suggest real differences between males and females with respect to the presence of genetically based differences among wild, lab, and hybrid individuals. Specifically, females of the two hybrid groups showed statistically significant differences in both sprint speed (11) and basal metabolic rate (35), thus indicating maternal effects. In contrast, we found no statistically significant tendency for the hybrids to differ for any trait measured herein. Figure 2 suggests a tendency for hybrid individuals to be faster if their mother was a lab mouse, but their female siblings showed the opposite trend (11).

The genes that account for differences between the wild and lab mice studied herein appear to have largely additive effects on the phenotypes we measured. For example, both maximal sprint running speeds and body masses of hybrid mice were almost perfectly intermediate between those of wild and lab mice (Fig. 2). Similarly, although wild and lab mice did not differ significantly in \% fiber type composition, hybrid mice clearly showed intermediate values (Tables 1, 2).

Relative gastrocnemius muscle masses of hybrid mice resembled those of wild mice (Fig. 3) rather than being intermediate between values for wild and lab mice. This result suggests net genetic dominance in the direction of the wild phenotype for relative gastrocnemius mass [or possibly for percent body fat: see above and cf. $(5,11,35)]$. Comparisons of other traits in the female siblings of these mice also showed several examples of net genetic dominance in the direction of the wild phenotype, e.g., for maximal oxygen consumption, ventricle mass, and several measures of activity on voluntary running wheels $(11,35)$.

After adjusting statistically for differences among group means and for body mass (which was significant only for gastrocnemius mass and fiber cross-sectional areas; age at testing was not significant for any character), individual differences in sprint speed (which were reproducible: see Fig. 1) were not significantly correlated with either relative gastrocnemius muscle mass (which was highly consistent between left and right muscles) or muscle fiber type cell size or distribution. Our data, however, cannot entirely eliminate fiber type characteristics as factors partly determining locomotor performance. Histochemical determination of fiber type metabolic characteristics is not sensitive to quantitative variation in metabolic capacity. Considerable metabolic heterogeneity can exist among fibers of identical histochemical characteristics, both within and among species of mammals (31-33). Thus, although our data indicate that similar fiber type distributions exist among wild, lab, and hybrid mice, they cannot eliminate the possibility that the fiber types of one or more groups may be faster contracting or more oxidative than are homologous fibers in another group. Arguing against this possibility, however, is the observation that fiber size did not differ significantly among groups. Previous studies have documented correlations between fiber size and metabolic capacity in rats and lizards $(18,37)$. In a previous study of 35 male Hsd:ICR mice, we reported a positive correlation between sprint speed and maximal oxygen consumption ( $\mathrm{VO}_{2} \mathrm{max}$ ) determined during forced treadmill exercise (13). In a larger study of about 300 Hsd:ICR mice, we also found no significant correlation between speed and gastrocnemius muscle mass (as noted above), and the correlation with $\dot{\mathrm{VO}}_{2}$ max was lower (10). Thus, the physiological bases of individual differences in maximal sprint speed in house mice remain obscure (cf. 17,23).

In conclusion, randombred lab mice of the Hsd:ICR strain exhibited lower forced maximal sprint running speeds than did wild house mice from a Wisconsin population (see also 11). Because all individuals were bred and raised under identical laboratory conditions, and hybrid individuals exhibited intermediate phenotypes, we can conclude that these differences are genetically based [although for females the hybrids tended to resemble their wild parents, indicating a maternal effect: (11)]. Fiber type composition of the gastrocnemius muscle showed a similar pattern of among-group variation (hybrids intermediate to wild and lab mice), although the magnitude of differences was much smaller and not statistically significant. Lab mice had signifi- 
cantly smaller relative gastrocnemius muscles (see 11 on females), but possible effects of differences in lean body mass have not been controlled. At the level of differences among individual mice, maximal sprint speed did not correlate either with fiber type composition or with relative gastrocnemius mass.

Taken together, the foregoing results suggest that unmeasured morphological or physiological characters, or behavioral/motivational factors, cause the variation in sprint speed observed herein, both between wild and lab mice and among individuals within these two populations. Although our sprint speed trials involved chasing individuals (apparently) as fast as they would run, we have no way of knowing that each and every individual was actually performing to its maximal abilities. In general, the importance of "mental factors" in determining athletic performance is not well understood [e.g., on humans see (4), pp. 220-221]. Another possibility is that wild and lab mice were responding differently to "fear" caused by placement in a novel environment (i.e., the racetrack). If so, then measured sprint speeds might become more similar over repeated trials as animals habituated to the testing regimen. Consistent with this idea, the wild mice ran significantly more slowly and the lab mice ran significantly faster on day 2 as compared to day 1 (see Fig. 1 and RESULTS). Repeated measurement of wild and lab individuals over several days (or weeks), and in multiple types of tests [e.g., open-field or voluntary wheel-running behavior $(11,13)]$ would allow further insight concerning the extent to which "motivation" or "fear" can account for differences in locomotor behavior; however, repeated testing could also lead to physical conditioning (e.g., 2,37), which might confound comparisons.

With respect to house mice, putative behavioral effectors of sprint performance do not appear to be related to the phenomenon of open-field "freezing" described for wild house mice by Smith (38) and others. Although we did observe freezing by the wild mice during incidental handling, it did not occur during measurement of sprint speed trials. In a previous study of 35 male Hsd:ICR mice, we found that forced maximal sprint speed was positively correlated with the voluntary maximal speed observed during an open-field test, as well as with maximal oxygen consumption recorded during a forced treadmill step-test (13). In any case, many previous workers have argued, on both theoretical and empirical grounds, that behavioral traits are likely to be among the first to change during domestication (e.g., 24). The small degree of differentiation in fiber type composition between lab and wild house mice reported herein probably cannot be explained by a lack of genetic variation $(28,29)$.

Several other issues would be worthy of further study. We do not know if our sampling of wild mice to obtain the parents of the offspring studied herein (and in 11,35) may have been biased with respect to genes affecting sprint speed. Conceivably, "capturability," fertility, tolerance to captivity, or even disease resistance might show genetic covariance with sprint speed as measured herein. This wild population did, however, test negative for the spirochete which causes Lyme disease (see 35) and for Hanta virus (Centers for Disease Control, pers. comm.). Moreover, as multiple capture times were employed (May-July 1992), the possibility of biased sampling may have been diminished. On the other hand, wild pairs produced significantly fewer litters ( 7 of 17) than did lab pairs (19 of 20) (see 35). Thus, we do not know how representative our comparisons may be, let alone whether they would yield similar results if a different population of wild mice, or a different strain of lab mice, were tested. Repeating the experiments with larger sample sizes would allow a definitive test of whether wild and lab mice differ in muscle properties. Finally, additional crosses, e.g., including the F2 and backcrosses, could be used to elucidate the number of genes responsible for the wild-lab differences observed herein (41).

\section{ACKNOWLEDGEMENTS}

This project was supported by a Karl Entemann fellowship (to M.R.D.), grants from the National Science Foundation (DEB-9157268 [Presidential Young Investigator Award] and IBN-9111185 to T.G), National Institutes of Health (RO1 DK46428 to T.T.G.), by the University of Wisconsin Graduate School, and by equipment donations from Lafayette Instrument Co. and San Diego Instruments. Comments of two anonymous referees improved the manuscript.

\section{REFERENCES}

1. Ariano, M. A.; Armstrong, R. B.; Edgerton, V. R. Hindlimb muscle fiber populations of five mammals. J. Histochem. Cytochem. 21:51$55 ; 1973$

2. Astrand, P. O.; Rodahl, K. Textbook of work physiology. 3rd ed. New York: McGraw-Hill; 1986.

3. Bennett, A. F. Inter-individual variability: An underutilized resource. In: Feder, M. E.; Bennett, A. F.; Burggren, W. W.; Huey, R. B., eds. New directions in ecological physiology. Cambridge, UK: Cambridge Univ. Press; 1987:147-169.

4. Birrer, R. G.; Levine, R. Performance parameters in children and adolescent athletes. Sports Med. 4:211-227; 1987.

5. Bouchard, C., ed. The genetics of obesity. Boca Raton, FL: CRC Press, Inc; 1994.

6. Bronson, F. H. Mammalian reproductive biology. Chicago: Univ. Chicago Press; 1989.

7. Brooke, M. H.; Kaiser, K. K. Three "myosin adenosine triphosphatase" systems: The nature of their $\mathrm{pH}$ lability and sulfhydryl dependence. J. Histochem. Cytochem. 18:670-672; 1970.

8. Bruell, J. H. Behavioral population genetics and wild Mus musculus. In: Lindzey, G.; Thiessen, D. D., eds. Contributions to behaviorgenetic analyses-The rnouse as a prototype. New York: AppletonCentury-Crofts; 1970:261-291.

9. Costill, D. L.; Daniels, J.; Evans, W.; Fink, W.; Krahenbuhl, G.; Saltin, B. Skeletal muscle enzymes and fiber composition in male and female track athletes. J. Appl. Physiol. 40:149-154; 1976.

10. Dohm, M. R. Quantitative genetics of locomotor performance and physiology in house mice. Unpubl. Ph.D. dissertation, Univ. of Wisconsin, Madison; 1994.

11. Dohm, M. R.; Richardson, C. S.; Garland, T., Jr. Exercise physiology of wild and random-bred laboratory house mice and their reciprocal hybrids. Am. J. Physiol. 267 (Regul. Integr. Comp. Physiol. 36): R1098-R1108; 1994.

12. Esbjörnsson, M.; Sylvén, C.; Holm, I.; Jansson, E. Fast twitch fibres may predict anaerobic performance in both females and males. Int. J. Sports Med. 14:257-263; 1993.

13. Friedman, W. A.; Garland, T., Jr.; Dohm, M. R. Individual variation in locomotor behavior and maximal oxygen consumption in mice. Physiol. Behav. 52:97-104; 1992.

14. Garland, T., Jr.; Adolph, S. C. Physiological differentiation of vertebrate populations. Annu. Rev. Ecol. Syst. 22:193-228; 1991.

15. Garland, T., Jr.; Carter, P. A. Evolutionary physiology. Annu. Rev. Physiol. 56:579-621; 1994.

16. Garland, T., Jr.; Geiser, F.; Baudinette, R. V. Comparative locomotor performance of marsupial and placental mammals. J. Zool. Lond. 215:505-522; 1988.

17. Garland, T., Jr.; Losos, J. B. Ecological morphology of locomotor performance in squamate reptiles. In: Wainwright, P. C.; Reilly, S. $M$, eds. Ecological morphology: Integrative organismal biology. Chicago: Univ. Chicago Press; 1994:240-302.

18. Gleeson, T. T.; Harrison, J. M. Muscle composition and its relation to sprint running in the lizard Dipsosaurus dorsalis. Am. J. Physiol. 255 (Regul. Integr. Comp. Physiol. 24):R470-R477; 1988. 
19. Gleeson, T. T.; Putnam, R. W.; Bennett, A. F. Histochemical, enzymatic, and contractile properties of skeletal muscle fibers in the lizard, Dipsosaurus dorsalis. J. Exp. Zool. 214:293-302; 1980.

20. Gunn, H. M. Adaptations of skeletal muscle that favour athletic ability. New Zealand Veter. J. 23:249-254; 1975.

21. Hayes, J. P.; Garland, T., Jr.; Dohm, M. R. Individual variation in metabolism and reproduction of Mus: Are energetics and life history linked? Funct. Ecol. 6:5-14; 1992.

22. Hoppeler, H.; Mathieu, O.; Krauer, R.; Claassen, H.; Armstrong, R. B.; Weibel, E. R. Design of the mammalian respiratory system. VI. Distribution of mitochondria and capillaries in various muscles. Respir. Physiol. 44:87-112; 1981.

23. Jones, J. H.; Lindstedt, S. L. Limits to maximal performance. Annu. Rev. Physiol. 55:547-569; 1993.

24. Kohane, M. J.; Parsons, P. A. Domestication: Evolutionary changes under stress. Evol. Biol. 23:31-48; 1988.

25. Komi, P. V.; Karlsson, J. Physical performance, skeletal muscle enzyme activities, and fiber types in monozygous and dizygous twins of both sexes. Acta Physiologica Scandinavica Supplementum 462; 1979.

26. Leopold, A. S. The nature of heritable wildness in turkeys. The Condor 46:133-197; 1944.

27. Morey, D. F. The early evolution of the domestic dog. Am. Scientist 82:336-347; 1994.

28. Nakamura, T.; Masui, S.; Wada, M.; Katoh, H.; Mikami, H.; Katsuta, S. Heredity of muscle fibre composition estimated from selection experiment in rats. Eur. J. Appl. Physiol. Occupat. Physiol. 66:85-89; 1993.

29. Nimmo, M. A.; Wilson, R. H.; Snow, D. H. The inheritance of skeletal muscle fibre composition in mice. Comp. Biochem. Physiol. 81A:109-115; 1985.

30. Peter, J. B.; Barnard, R. J., Edgerton, V. R.; Gillespie, C. A.; Stempel, K. E. Metabolic profiles of three fiber types of skeletal muscle in guinea pigs and rabbits. Biochemistry 11:2627-2633; 1972.

31. Pette, D. Metabolic heterogeneity of muscle fibers. J. Exp. Biol. 115:179-189; 1985.

32. Pette, D.; Staron, R. S. Cellular and molecular diversities of mammalian skeletal muscle fibers. Rev. Physiol. Biochem. Pharmacol. 116:1-75; 1990.

33. Pette, D.; Staron, R. S. The molecular diversity of mammalian muscle fibers. News Physiol. Sci. 8:153-157; 1993.

34. Price, E. O. Behavioral aspects of animal domestication. Quart. Rev. Biol. 59:1-32; 1984.

35. Richardson, C. S.; Dohm, M. R.; Garland, T., Jr. Metabolism and thermoregulation in crosses between wild and random-bred laboratory house mice (Mus domesticus). Physiol. Zool. 67:944-975; 1994.

36. Rivero, J.-L. L.; Serrano, A. L.; Henckel, P.; Agüera, E. Muscle fiber type composition and fiber size in successfully and unsuccessfully endurance-raced horses. J. Appl. Physiol. 75:1758-1766; 1993.

37. Roy, R. R.; Bello, M. A.; Bouissou, P., Edgerton, V. R. Size and metabolic properties of fibers in rat fast-twitch muscles after hindlimb suspension. J. Appl. Physiol. 62:2348-2357; 1987.

38. Smith, R. H. Open-field freezing as a stable parameter of wildness in Mus musculus. Behav. Biol. 23:67-74; 1978.

39. Smith, R. H. Behavioral measures of drift in Mus musculus. Behav. Genet. 15:483-497; 1985.

40. Snow, D. H.; Harris, R. C. Thoroughbreds and greyhounds: Biochemical adaptations in creatures of nature and of man. In: Gilles, R., ed. Circulation, respiration, and metabolism. Berlin: Springer-Verlag; 1985:227-239.

41. Zeng, Z.-B. Correcting the bias of Wright's estimates of the number of genes affecting a quantitative character: A further improved method. Genetics 131:987-1001; 1992. 